\title{
TCOM \\ Gender-biased public perception of STEM fields, focusing on the influence of egalitarian attitudes toward gender roles
}

\section{Yuko Ikkatai, Azusa Minamizaki, Kei Kano, Atsushi Inoue, Euan McKay and Hiromi M. Yokoyama}

Abstract

Many studies have examined the impression that the general public has of science and how this can prevent girls from choosing science fields. Using an online questionnaire, we investigated whether the public perception of several academic fields was gender-biased in Japan. First, we found the gender-bias gap in public perceptions was largest in nursing and mechanical engineering. Second, people who have a low level of egalitarian attitudes toward gender roles perceived that nursing was suitable for women. Third, people who have a low level of egalitarian attitudes perceived that many STEM fields are suitable for men. This suggests that gender-biased perceptions toward academic fields can still be found in Japan.

Keywords

DOI

Public engagement with science and technology; Public perception of science and technology; Women in science

https://doi.org/10.22323/2.19010208

Submitted: 6th February 2019

Accepted: 24th January 2020

Published: 9th March 2020

Introduction

The underrepresentation of women can be seen around the world in science fields, but, in general, there are more women in the life sciences and fewer women in the physical sciences [Organisation for Economic Cooperation and Development, 2015]. A long-term survey in the US showed that the proportion of all first-year female college students who reported their intention to major in science fields (biology, computer science, engineering, math/statistics, and physics) differed depending on the field, but this figure had been consistently less than 20 percent for four decades, across all fields [Sax et al., 2016]. This study also showed that the number of female students who reported their intention to major in biology had increased from four to 16 percent from 1971 to 2011, but that the number of intended majors in physics, chemistry, and mathematics had remained at or below one percent for four decades. 
Several possible factors have been proposed for what influences high school students when they choose their majors. External factors include the ways in which students are affected by their parents, teachers, and friends. Mothers play a particularly important role, especially for girls. Mothers' perceptions of their daughters' abilities in math were found to be significantly related to later career choices [Bleeker and Jacobs, 2004]. Regarding possible internal factors, it may be that girls are often affected by the stereotype threat phenomenon: some girls unconsciously perform less well in mathematics in order to conform to the stereotype that boys are better than girls at mathematics [Spencer, Steele and Quinn, 1999; Spencer, Logel and Davies, 2016]. However, a previous study suggest that the impact of stereotype threat can be reduced by some form of psychological intervention. For example, women performed as well as men at mathematics when they were instructed to read a sentence stating that there was no gender difference in mathematics [Spencer, Steele and Quinn, 1999]. However, especially for a girl aspiring to be a scientist, a masculine image of a science field, such as mathematics, physics, and engineering, could be discouraging. Cheryan et al. proposed a model that explains women's lower representation in computer science, engineering, and physics in the US using three factors: "masculine culture of the fields," "insufficient early experience," and "gender gaps in self-efficacy" [Cheryan et al., 2017]. This model suggests that the perceptions of science fields are gender-biased.

\section{Women in STEM in Japan}

Women are in the minority in physical sciences also in Japan. In 2017, the percentage of female students were less than 20 percent in physics and mathematics, 10 percent in mechanical engineering (Figure 1a), while there were more female students in medical fields (especially nursing, Figure $1 \mathrm{~b}$ ) as well as the humanities and the social science fields (Figure 1c). In these situations, Japanese girls may have the stereotypical view that girls do not have an aptitude for hard science but boys do. A research has shown that the percentage of girls in Japan who thought that boys had an aptitude for mathematics was 20 percent in elementary school (boys, 36 percent), but it rose to 32 percent in high school (boys, 32 percent), ${ }^{1}$ suggesting that girls perceive mathematics as a boys' field.

In Japan, the subjects required for entrance examinations for universities vary depending on the major. In most of the high schools in Japan, students choose either science or humanities courses in their first or second year (when they are 15 or 16 years old). Science courses have four branches: physics, chemistry, biology, and earth science. In line with the national curriculum, students have to choose three basic courses that are compulsory from these four fields as well as advanced courses as electives [Ministry of Education, Culture, Sports, Science and Technology, 2016]. The percentage of girls who thought girls had an aptitude for science courses was 40 percent in elementary school (boys, 60 percent), but dropped to 28 percent in high school (boys, 47 percent). We estimated that only about four percent of female students took advanced physics classes in high school over the period from 2005 to 2011, even though most physics and engineering

\footnotetext{
${ }^{1}$ Official website of Benesse (in Japanese), https:/ / benesse.jp/kyouiku/201712/20171204-2.html, accessed on 18 December 2019.
} 
departments require physics for their entrance examination. ${ }^{2}$ Therefore, high school students have to make decisions on their future major early on. As a result, the general perception that Japanese students have of academic fields could be more important than for students in other countries, where students can choose their majors after entering university.

Image of science and egalitarian attitudes for gender roles in Japan

Japan has produced more than 20 Nobel Prize laureates in physics, chemistry, physiology, and medicine, but they have all been men. Interestingly, the occupation physicist is recognized as being especially masculine in Japan [Adachi, 2014]. Masculine images associated with science and technology can also be found in Japanese television programs for children. One recent example is Kamen Rider Build (2017-2018) where the superhero was portrayed as a "genius" physicist who uses the law of physics as a weapon to defeat his enemies. ${ }^{3}$

On the other hand, the idea that science and higher education are not for girls is deeply rooted in Japanese society. Just as the American Barbie doll used to say "Math class is tough" [Schiebinger, 1999], the popular Japanese Licca doll ${ }^{4}$ was originally characterized as being poor at mathematics [Ogawa, Frehill and Huyer, 2012]. These trends have improved in recent years; today, there are now many Barbies whose occupations are related to science, such as robotics engineer. ${ }^{5}$

These stereotypical gender views could be closely related to the lifestyle during the period of rapid economic growth after the late 1950s in Japan. The view of families where husbands worked outside and wives did housework at home used to be common in Japan [Ministry of Health, Labor and Welfare, 2018]. However, single-income households started to be outnumbered by double-income households at least until the late 1990s [Gender Equality Bureau Cabinet Office, 2018]. Today, however, both men and women work outside the home. Dual-income families are becoming much more common. Nonetheless, the conservative Japanese approach is still strong, and gender roles have not markedly changed.

Additionally, Japan's gender gap is still among the widest in the world. The Gender Gap Index (GGI) is an index that measures gender inequality focusing on four dimensions: economic participation and opportunity, educational attainment, health and survival, and political empowerment [World Economic Forum, 2018]. In 2018, the ranking for Japan in the GGI was 110 out of 149, suggesting that there would be many people who have a strong attitude toward gender roles. People

\footnotetext{
${ }^{2}$ From 2005 to 2011, when two science fields from among biology, physics, chemistry and earth science were needed for a required course at high school, students who chose physics II (advanced physics class) were only about 20 percent of the total [Science Council of Japan, 2016]. At the same time, boys dominated physics II class ( 80 percent boys and 20 percent girls) [Center for Promotion of Science Education, Japan Science and Technology Agency, 2010]. Based on these two documents, high school girls who chose physics II were presumed to account for only 4 percent of all girls in high school.

${ }^{3}$ Official website of Kamen Rider Build, https:/ / www.tv-asahi.co.jp/build/, accessed on 18 December 2019.

${ }^{4}$ Official website of Licca dolls by Tomy Company, Ltd., https:/ /licca.takaratomy.co.jp/, accessed on 18 December 2019.

5 "Barbie Adds New STEM Career To Her Resume," https:/ / news.mattel.com/news/barbie-174-adds-new-stem-career-to-her-resume, accessed on 18 December 2019.
} 
(a) Science fields (except for medical fields)

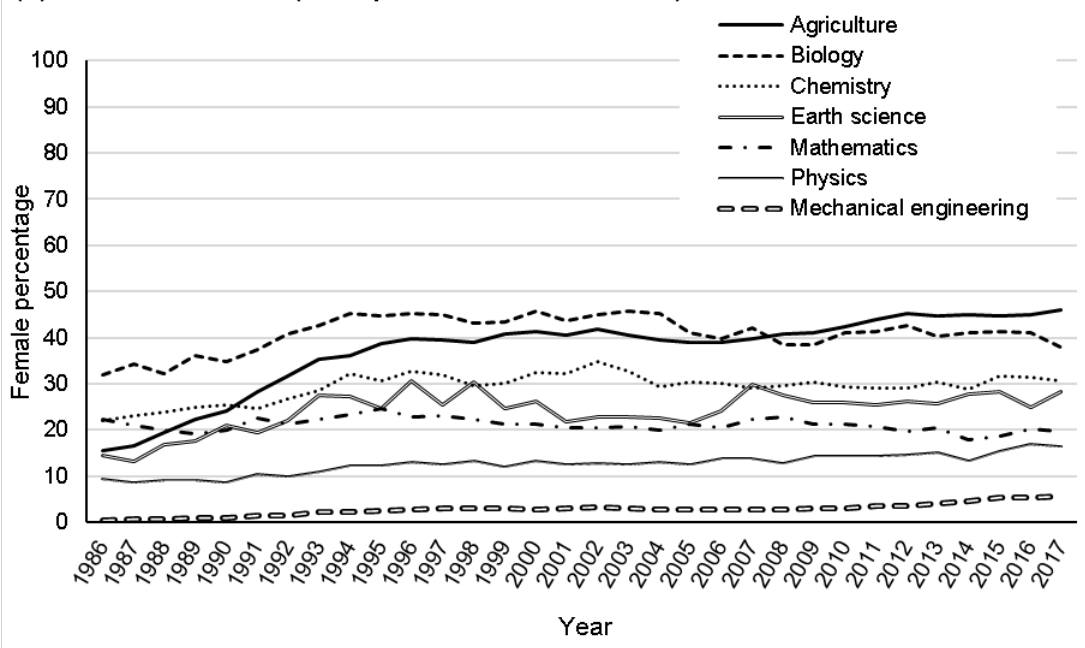

(b) Medical fields

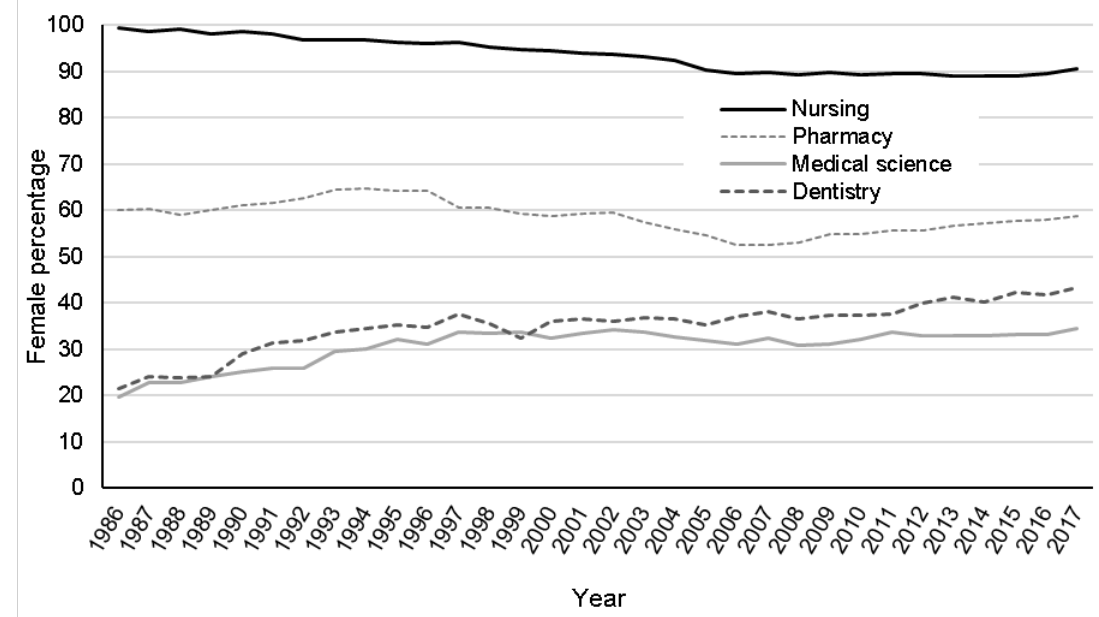

(c) Social science, humanities and other fields

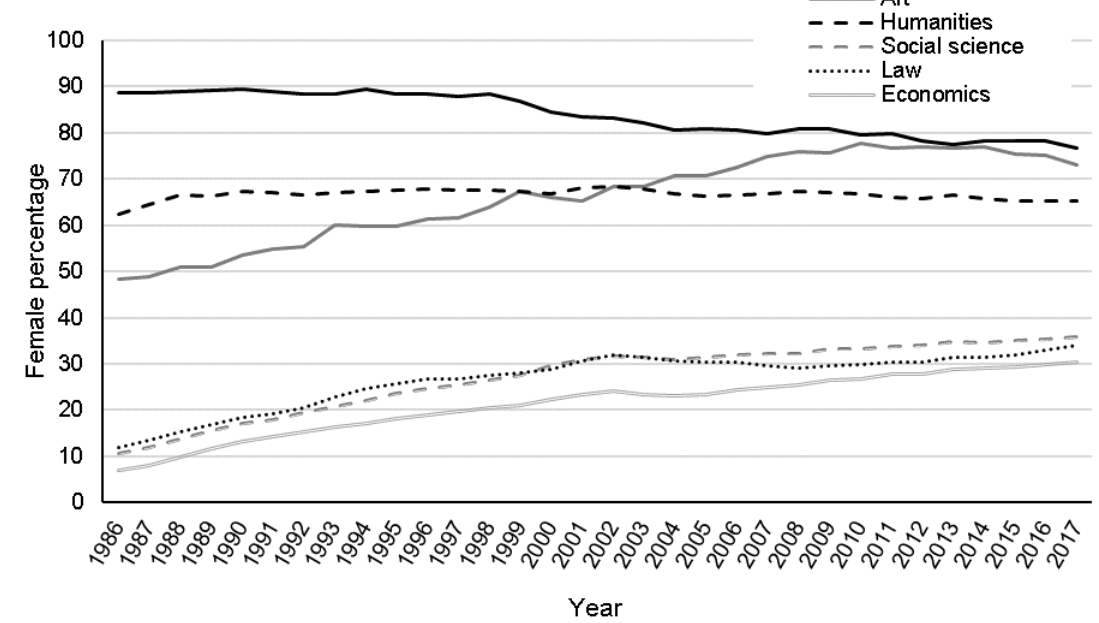

Figure 1. Percentage of female university enrollments in Japan in (a) science fields (except for medical fields), (b) medical fields and (c) social science, humanities and other fields, based on a survey Gakkō kihon chōsa [Statistics of Japan, 2020a]. 
who have a low level of egalitarian attitudes for gender roles may have the strong stereotypical view that science is suitable for men and not for women. However, the relationship between the level of egalitarian attitude and the gender perception of science fields has not been examined in Japan.

In this study, we subdivided the images of suitability into three in relation to the level of egalitarian attitudes for gender roles: gender suitability, employment suitability, and marriage suitability.

Gender suitability is the summative view that people consider that a certain field is suitable for women or men. Considering the situation that there are more men and fewer women in some of science fields in Japan, there would be some people who perceive that those fields are not suitable for women but are suitable for men.

Employment suitability is the view that people consider that a field is suitable for women or men from the viewpoint of their careers after graduation. For example, some majors, such as engineering, medicine, or nursing, lead students to particular jobs, so perceptions of careers after graduation could be associated with the impressions of majors. There was a belief in Japan that girls rarely chose engineering because people working in these fields needed to belong to organizations with a masculine culture. Mothers who know the difficulty for women to work as minorities in organizations with a masculine culture do not recommend to their daughters that they belong to male-dominated societies [Ueno, 2018]. Therefore, science fields, including engineering, could be perceived as "good" for men but "bad" for women based on the view of future job opportunities. However, as far as the authors of this study know, it has not been examined whether the perception of employment suitability differs between men and women.

Marriage suitability is the view that people consider that a field is suitable for women or men from the viewpoint of marriage opportunities. It may seem strange to focus on marriage in an age when diversity is being emphasized. However, until the 1990s when the Japanese economy was good, it had been common for women working as housewives. Some people believed that, for girls, science fields would be disadvantageous when they got married for becoming a good mother and wife. Today, two-income families are becoming common even after marriage; some people however may still perceive that science fields are not good for girls from the viewpoint of marriage, though this has not been examined before.

Research questions
In this study, we investigated the gender perceptions of STEM fields using an online questionnaire focusing on the influence of egalitarian attitudes towards gender roles. Since the definition of STEM is still being debated [e.g Gonzalez and Kuenzi, 2012], in this paper we defined STEM as science, technology, engineering, mathematics, and medical fields. We measured the level of individual egalitarian attitudes for gender roles using the Scale of Egalitarian Sex Role Attitudes (SESRA-S) developed in psychology. This scale included 15 questions with three categories: marriage, parenting and working [Suzuki, 1994; Ui, 2001; Uji et al., 2006]. The total scores of the 15 questions (from 15 to 75) show the level of individual egalitarian attitudes for gender roles. The coefficient reliability was reported as 0.91 [Suzuki, 1994]. The lower the total score is, the more the person 
had a lower egalitarian attitude. More specifically, the person with lower level attitude strongly agree to stereotypical gender role view such as "women at home and men at work (Table 2, No.4)", "women should not work even after having a child (Table 2, No. 13)" and "bringing up children is the most important job for women (Table 2, No. 8)". Among Japanese people who graduated from college or higher level, the score for women $(\mathrm{n}=57$, average $\pm \mathrm{SD}=57.93 \pm 8.65)$ was higher than for men [ $\mathrm{n}=106,46.77 \pm 10.13$; Suzuki, 1994]. However, the score for Japanese women was lower than that of American women [Suzuki, 1991], demonstrating that the Japanese public would have a lower level of egalitarian attitudes for gender roles. We used 18 academic fields: 12 STEM fields (mathematics, chemistry, physics, mechanical engineering, information science, biology, agriculture, earth science, medical science, dentistry, pharmacy, and nursing) and other six fields (law, economics, social science, humanities, music, and art) to compare with STEM fields. The research questions were:

- RQ1: Is there a gender bias for academic fields in Japanese public perceptions regarding gender suitability, employment suitability, and marriage suitability?

- RQ2: Does the perception of women's suitability for STEM fields differ by the level of egalitarian attitude toward gender roles?

- RQ3: Does the perception of men's suitability for STEM fields differ by the level of egalitarian attitude toward gender roles?

We conducted an online survey to investigate whether the public perception of 18 academic fields was gender-biased in Japan. We collected responses from 1,086 members of the public $($ men $=541$, women $=545)$ aged from 20 to 69. These samples matched the current demographic profile of the Japanese population. The authors employed Macromill, Inc., a research company in Japan, to collect the data online using the company's data pool. Macromill sent an email to registrants who met our criteria requesting their participation. Data collection was stopped soon after the number of responses reached the pre-defined number of responses $(\mathrm{n}=$ 1,000). This survey was conducted on March 1 and 2, 2018. All responses were considered valid.

\section{Questionnaire}

The questionnaire included personal information, a survey of egalitarian attitudes toward gender roles, and a survey of public gender-biased perceptions of the suitability of 18 academic fields. The details are shown below.

- Personal information included gender, age, and educational achievement (less than high school, associate's degree, bachelor's degree, postgraduate degree, and others; see Table 1). 
- Egalitarian attitudes regarding gender roles were measured using the Japanese version of the short form of the Scale of Egalitarian Sex Role Attitudes (SESRA-S). SESRA-S consisting of 15 items about gender roles [Suzuki, 1994; Ui, 2001; Uji et al., 2006]. The participants were asked to rate each question on a five-point Likert scale (from strongly disagree $=1$ to strongly agree $=5$ ). The 15 questions consisted of four non-reversed items and 11 reversed items. The five-point scale was reversed in the reversed items when calculating the total score for SESRA-S. The total scores for the 15 questions were calculated as SESRA-S scores (ranging from 15 to 75). In this study, the mean $\pm \mathrm{SD}$ of the participants was $52.15 \pm 9.41(\mathrm{n}=1,086, \max =$ 75 , min $=15$ ). The item that scored the highest was "domestic chores should be shared between spouses." (3.88 \pm 0.96 , Table 2$)$.

- Public gender-biased perceptions of suitability were examined by focusing on (a) gender suitability, (b) employment suitability, and (c) marriage suitability. The questions for investigating (a) gender suitability were (a1) Do you think women are suited to this field? and (a2) Do you think men are suited to this field? The questions for investigating (b) employment suitability were (b1) Do you think women can find employment in this field? and (2) Do you think men can find employment in this field? The questions for investigating (c) marriage suitability were (c1) Do you think women in this field have an advantage when seeking marriage? and (c2) Do you think men in this field have an advantage when seeking marriage? The participants rated how strongly they agreed or disagreed using a five-point Likert scale (from strongly disagree $=1$ to strongly agree $=5$ ).

We listed 18 academic fields: 12 STEM fields (mathematics, chemistry, physics, mechanical engineering, information science, biology, agriculture, earth science, medical science, dentistry, pharmacy, and nursing) and other fields (law, economics, social science, humanities, music, and art).

Table 1. Demographic information of the participants.

\begin{tabular}{|llccccc|}
\hline & & $\mathrm{n}$ & Mean & SD & Min. & Max. \\
\hline \multirow{2}{*}{ Gender } & Men & 541 & - & - & - & - \\
& Women & 545 & - & - & - & - \\
\hline Age & & 1086 & 45.76 & 13.71 & 20 & 69 \\
\hline \multirow{3}{*}{ Educational } & Less than high school/other & 351 & - & - & - & - \\
attainment & Associate's degree & 265 & - & - & - & - \\
& Bachelor's degree & 405 & - & - & - & - \\
& Postgraduate degree & 65 & - & - & - & - \\
\hline
\end{tabular}

\section{Analysis}

To investigate the gender bias between the perception for women and men, we calculated a "gender-gap score" of suitability. This score was calculated by comparing the five-point scale answers about women with those of men, as follows: (a) gender suitability (a1 minus a2), (b) employment suitability (b1 minus b2) and (c) marriage suitability (c1 minus c2). A large positive value for the resultant gender-gap score meant that the participant perceived that (a) women are 
Table 2. Items and SESRA-S scores.

\begin{tabular}{|c|c|c|c|c|}
\hline Category & No & Item & Mean & SD \\
\hline \multicolumn{5}{|c|}{ 1: strongly disagree -5 : strongly agree } \\
\hline Marriage & 7 & Domestic chores should be shared between spouses. & 3.88 & 0.96 \\
\hline Marriage & 2 & Important issues should be decided by husbands.* & 3.86 & 0.99 \\
\hline Parenting & 10 & Daughters should be raised to become housewives and sons to have jobs* & 3.84 & 1.02 \\
\hline Marriage & 4 & Women at home and men at work.* & 3.84 & 1.06 \\
\hline Marriage & 1 & Women in high social positions have difficulty getting married.* & 3.77 & 0.99 \\
\hline Marriage & 5 & Working women put a strain on the family.* & 3.58 & 1.02 \\
\hline Marriage & 3 & Working wives cause marital disharmony.* & 3.58 & 1.03 \\
\hline Working & 12 & Working outside is equally important for women & 3.52 & 0.94 \\
\hline Working & 11 & Women should work part-time because they have to raise children.* & 3.42 & 1.06 \\
\hline Working & 13 & Women should work even after having a child & 3.35 & 0.88 \\
\hline Marriage & 6 & No necessity to change surname after marriage & 3.33 & 1.10 \\
\hline Working & 15 & Women should not get a job with responsibility and competition.* & 3.26 & 1.01 \\
\hline Parenting & 9 & It is important to raise a boy to be masculine and a girl to be feminine.* & 3.03 & 1.10 \\
\hline Working & 14 & Women do not have to work if there is no economic need.* & 2.98 & 1.02 \\
\hline Parenting & 8 & Bringing up children is the most important job for women.* & 2.91 & 1.04 \\
\hline
\end{tabular}

Note. *reversed items. The mean scores shown have been reversed. Higher scores show a more gender equal attitude.

more suited to the field than men, (b) women in the field could find employment more easily than men and (c) the field was more advantageous for women when seeking marriage than for men.

We investigated the relationship between the level of egalitarian attitudes for gender roles and the perception of gender suitability. Looking at the level of the attitudes, we classified the participants into three groups based on the SESRA-S score: low (scoring from 15 to 34), moderate (scoring from 35 to 54) and high (scoring from 55 to 75). The low group was considered to have biased attitudes toward gender roles, while the high group was supportive of gender equality. The responses for perception of suitability were also classified into three: suitable (strongly agree, agree), neutral (neither) and unsuitable (disagree, strongly disagree). The relationships among the groups (low, moderate, and high) and the perceptions of gender suitability (suitable, neutral, and unsuitable) were analyzed using Fisher's exact test. A statistically significant level was $p<0.05$. All the analysis was conducted using $\mathrm{R}$ version 3.4.3.

\section{Results}

\section{Public perception of 18 academic fields}

There was a gender-biased perception regarding gender suitability for various fields. Women were perceived to be best-suited to nursing and least-suited to mechanical engineering. Music, art, humanities and economics, which were not STEM fields, ranked among the top nine fields for women (Figure 2a). Conversely, for men, eight out of top nine fields were STEM (Figure 2b). Mechanical engineering was perceived to be the best and biology was perceived to be the worst.

Looking at perceptions of employment suitability, nursing ranked the highest and earth science was perceived to be the worst for women (Figure 3a). For men, 
medical science was ranked the highest and music ranked the worst. Overall, nursing ranked third, a good score among the various fields (Figure $3 \mathrm{~b}$ ). The top four fields for both men and women were all medical fields: nursing, medical science, pharmacy, and dentistry.

For the perceptions of marriage suitability, music was perceived to be the best for women, while medical science was perceived to be the best for men. Music ranked lower for men, while pharmacy and dentistry ranked in the top three fields for both women and men (Figure 4a, Figure 4b). More than 50 percent of the participants "strongly agreed" or "agreed" that both women and men in these fields have an advantage in relation to marriage. Physics ranked seventh from the bottom for both women and men. This suggests that the perception gap for marriage among the various fields is smaller than the perception gap for suitability and employment.

(a) Do you think women are suited to this field?

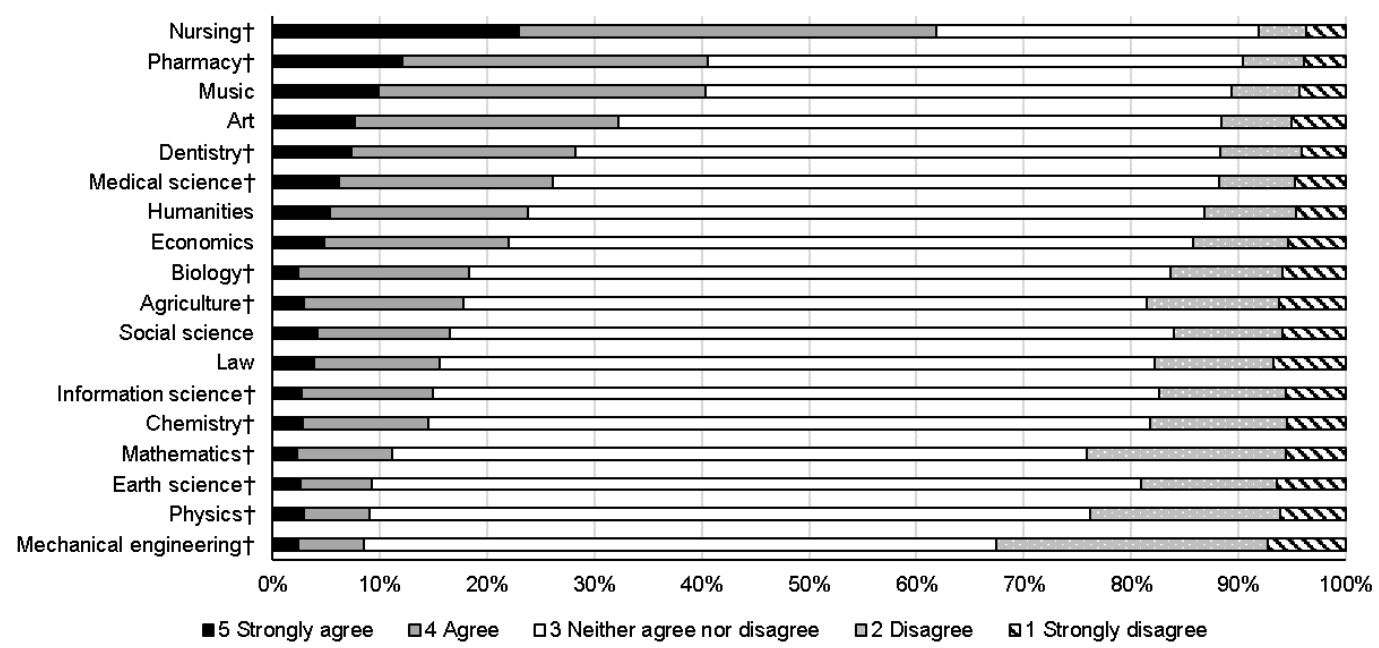

(b) Do you think men are suited to this field?

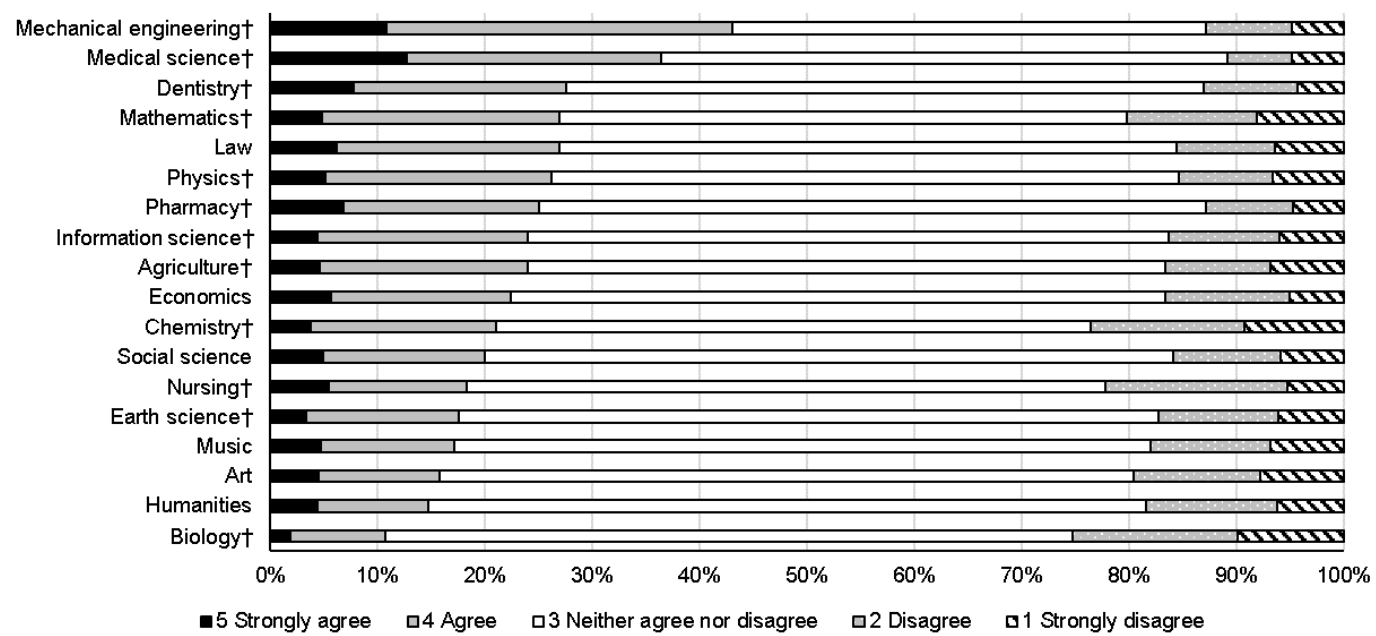

Figure 2. Gender-related public perception of 18 academic fields, expressed in terms of gender suitability for women (a) and men (b). The fields are arranged in order with the highest percentage agreement at the top, $n=1,086$. tsignifies STEM fields. 
(a) Do you think women can find employment in this field?

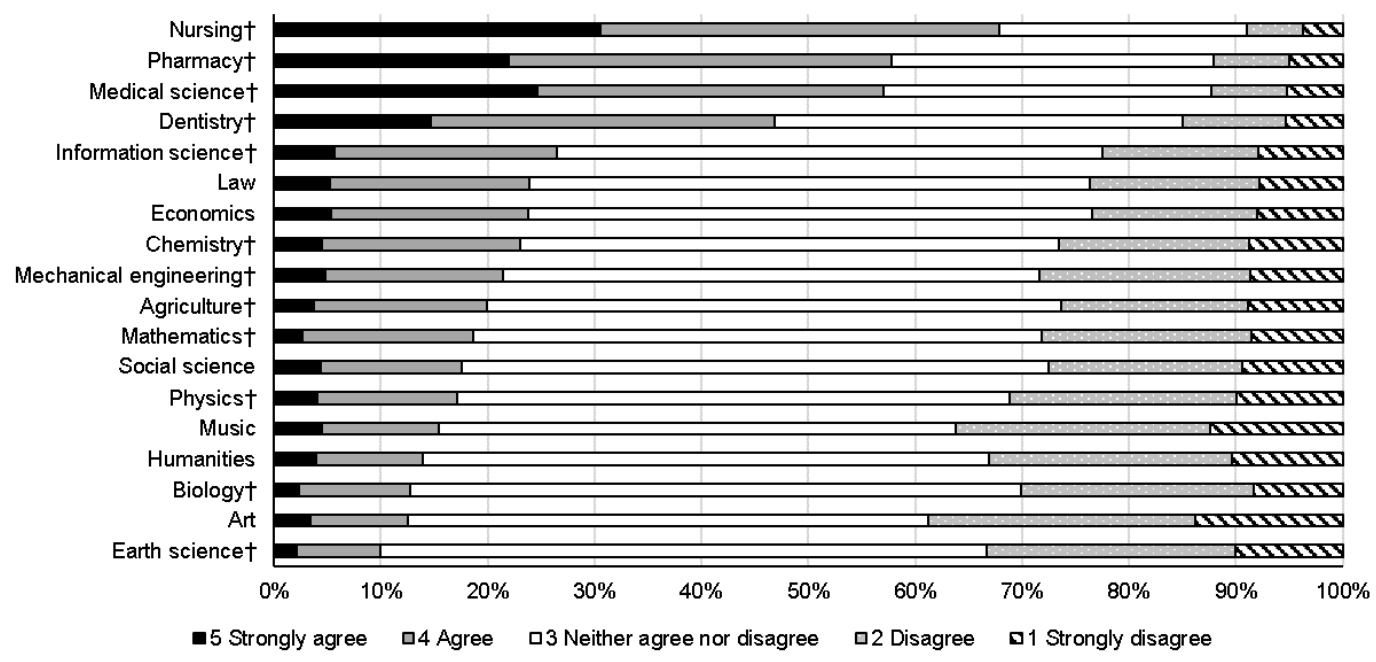

(b) Do you think men can find employment in this field?

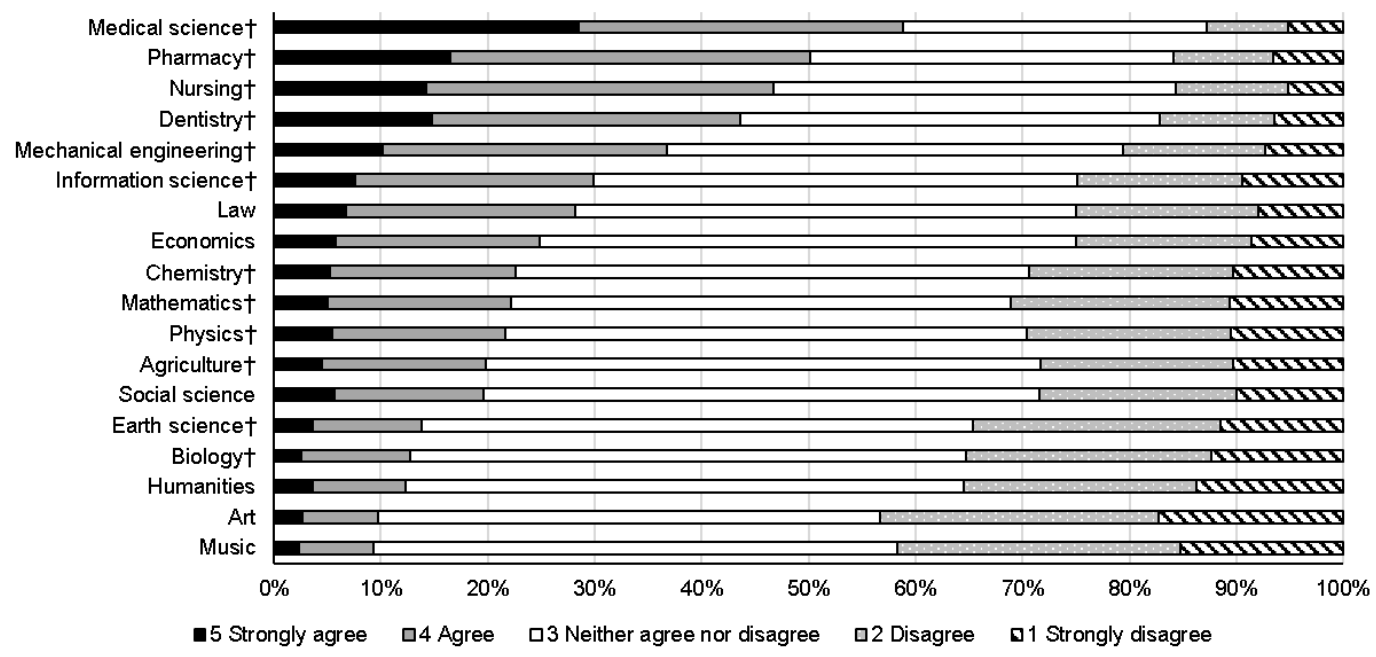

Figure 3. Gender-related public perception of 18 academic fields, expressed in terms of employment suitability for women (a) and men (b). The fields are arranged in order with the highest percentage agreement at the top, $\mathrm{n}=1,086$. tsignifies STEM fields.

\section{Gender-gap scores}

The range of mean gender-gap scores was higher for gender suitability (from -0.65 to 0.77 , Table 3 ) than employment suitability and marriage suitability.

The highest gender-gap score for gender suitability was found in nursing (mean \pm $\mathrm{SD}=0.77 \pm 1.11)$ and the lowest in mechanical engineering $(-0.65 \pm 1.19)$. The gender-gap score for employment suitability was also highest for nursing $(0.46 \pm$ 0.92 ), but the range was smaller than gender suitability (from -0.30 to 0.46 , Table 3 ). The lowest was found in mechanical engineering $(-0.30 \pm 0.89)$. The gender-gap score for marriage suitability was highest in music $(0.15 \pm 0.84)$ and lowest in medical science $(-0.29 \pm 0.97)$. 
(a) Do you think women in this field have an advantage when seeking marriage?

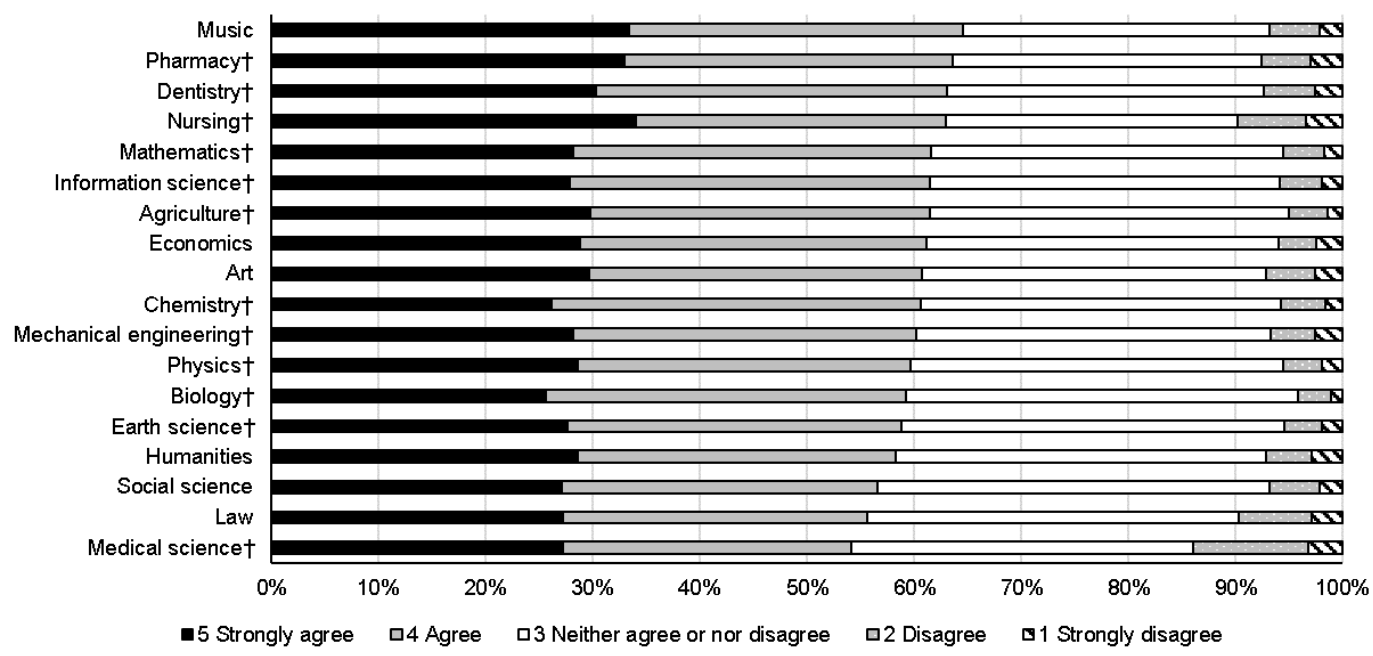

(b) Do you think men in this field have an advantage when seeking marriage?

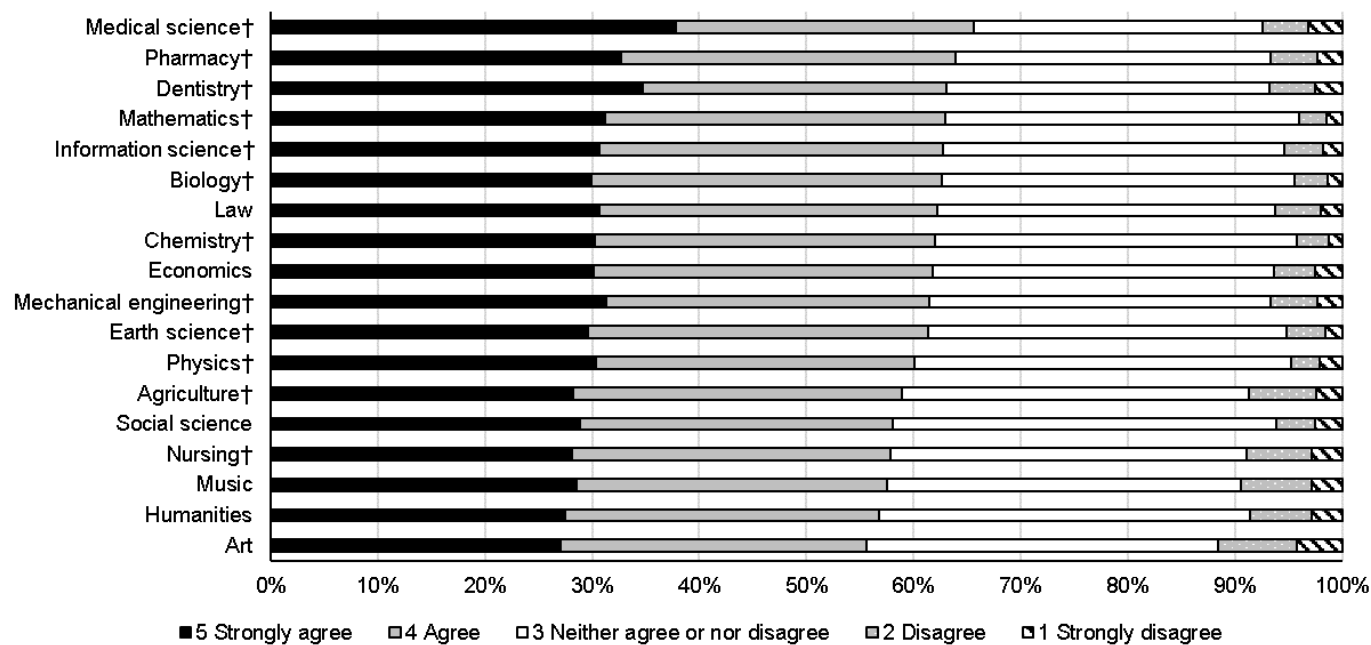

Figure 4. Gender-related public perception of 18 academic fields, expressed in terms of marriage suitability for women (a) and men (b). The fields are arranged in order with the highest percentage agreement at the top, $\mathrm{n}=1,086$. tsignifies STEM fields.

These results suggest that there was a large gender gap between women and men in the perception of gender suitability. Based on these results, we investigated gender suitability, among the three kinds of suitability, for further analysis.

\section{Egalitarian attitudes for gender roles}

The percentage of the low group with egalitarian attitudes for gender roles was small (low, $\mathrm{n}=29$, mean $\pm \mathrm{SD}=29.69 \pm 4.71$; moderate, $\mathrm{n}=635,46.93 \pm 4.85$; high $n=422,61.53 \pm 5.21)$. The percentage of men was larger than women in the low and moderate group, but not in high group (Table 4). 
Table 3. Gender-gap scores regarding (a) gender suitability, (b) employment suitability and (c) marriage suitability. This score was calculated by comparing the five-point scale answers about women with those of men. A large positive value for the resultant gender-gap score meant that the participant perceived that (a) women are more suited to the field than men, (b) women in the field could find employment more easily than men and (c) the field was more advantageous for women when seeking marriage than for men. The fields are arranged in order with high scores at the top. tsignifies STEM fields.

\begin{tabular}{|c|c|c|c|c|c|c|c|c|}
\hline \multicolumn{3}{|c|}{ Gender suitability } & \multicolumn{3}{|c|}{ Employment suitability } & \multicolumn{3}{|c|}{ Marriage suitability } \\
\hline Fields & Mean & SD & Fields & Mean & SD & Fields & Mean & SD \\
\hline Nursingt & 0.77 & 1.11 & Nursing + & 0.46 & 0.92 & Music & 0.15 & 0.84 \\
\hline Music & 0.38 & 0.91 & Pharmacyt & 0.18 & 0.87 & Art & 0.14 & 0.84 \\
\hline Art & 0.30 & 0.92 & Music & 0.17 & 0.76 & Nursing + & 0.10 & 0.89 \\
\hline Pharmacy ${ }^{\dagger}$ & 0.25 & 0.92 & Art & 0.12 & 0.78 & Agriculturet & 0.08 & 0.78 \\
\hline Biologyt & 0.21 & 0.91 & Biologyt & 0.09 & 0.73 & Humanities & 0.04 & 0.80 \\
\hline Humanities & 0.17 & 0.90 & Humanities & 0.08 & 0.79 & Economics & -0.02 & 0.73 \\
\hline Dentistry† & 0.02 & 0.83 & Dentistry† & 0.06 & 0.79 & Pharmacy† & -0.02 & 0.76 \\
\hline Chemistry & 0.02 & 1.05 & Chemistry† & 0.04 & 0.84 & Physicst & -0.03 & 0.75 \\
\hline Economics & 0.01 & 0.81 & Agriculturet & 0.03 & 0.77 & Social science & -0.04 & 0.78 \\
\hline Social science & -0.04 & 0.80 & Economics & 0.01 & 0.81 & $\begin{array}{l}\text { Mechanical } \\
\text { engineering } †\end{array}$ & -0.05 & 0.83 \\
\hline Agriculturet & -0.09 & 0.89 & Mathematics + & -0.01 & 0.84 & $\begin{array}{l}\text { Information } \\
\text { sciencet }\end{array}$ & -0.05 & 0.69 \\
\hline Earth sciencet & -0.11 & 0.87 & $\begin{array}{l}\text { Information } \\
\text { sciencet }\end{array}$ & -0.01 & 0.80 & Dentistry† & -0.05 & 0.83 \\
\hline $\begin{array}{l}\text { Information } \\
\text { sciencet }\end{array}$ & -0.12 & 0.87 & Social science & -0.02 & 0.85 & Earth sciencet & -0.05 & 0.71 \\
\hline Law & -0.16 & 0.95 & Earth sciencet & -0.03 & 0.71 & Mathematicst & -0.06 & 0.75 \\
\hline Medical sciencet & -0.17 & 0.90 & Law & -0.04 & 0.79 & Biologyt & -0.07 & 0.71 \\
\hline Mathematicst & -0.20 & 1.14 & Medical sciencet & -0.05 & 0.77 & Chemistry† & -0.08 & 0.73 \\
\hline Physicst & -0.27 & 0.98 & Physicst & -0.07 & 0.78 & Law & -0.15 & 0.81 \\
\hline $\begin{array}{l}\text { Mechanical } \\
\text { engineering† }\end{array}$ & -0.65 & 1.19 & $\begin{array}{l}\text { Mechanical } \\
\text { engineering† }\end{array}$ & -0.30 & 0.89 & Medical sciencet & -0.29 & 0.97 \\
\hline
\end{tabular}

Table 4. Profiles of the three groups based on SESRA-S scores.

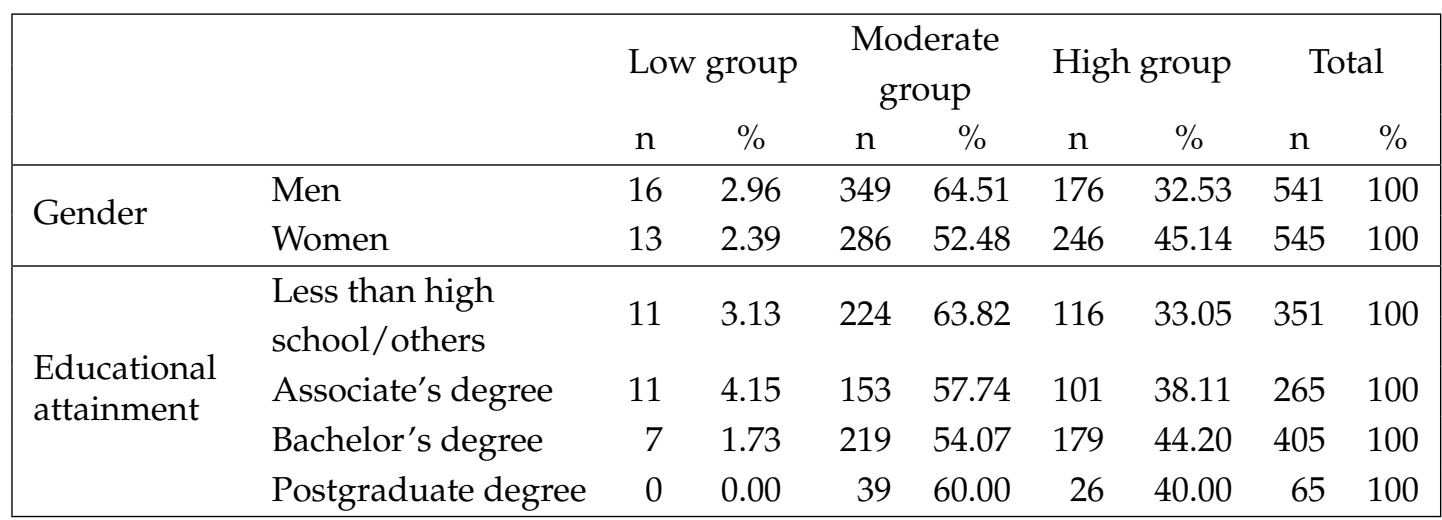

Egalitarian attitudes for gender roles and the perception of women's gender suitability

We investigated the relationship between the level of egalitarian attitudes and the perception of women's gender suitability. Significant differences were found only 
in four fields (Fisher's test, nursing, $p<0.001$; pharmacy, $p=0.037$; music, $p<0.001$; law, $p=0.012$ ). It suggests that, for example, people in the low group perceived that nursing are suitable for women, but people in the high group did not have that perception (Figure 5a). Significant differences between the two factors were not found in the other 14 fields: Fisher's test, biology, $p=0.238$; agriculture, $p=0.231$; social science, $p=0.889$; information science, $p=0.569$; chemistry, $p=0.643$; mathematics, $p=0.824$; earth science, $p=0.995$; physics, $p=0.595$; mechanical engineering, $p=0.347$, Figure 6a; art, $p=0.180$; density, $p=0.417$; medical science, $p$ $=0.265$; and humanities, $p=0.962$; economics, $p=0.391$.

\section{Egalitarian attitudes for gender roles and the perception of men's gender suitability}

A significant difference was found among the three levels of egalitarian attitudes and the perception of men's gender suitability in 15 fields (Fisher's test, physics, $p$ $<0.001$; chemistry, $p<0.001$; biology, $p<0.001$; mathematics, $p<0.001$; earth science, $p<0.001$; agriculture, $p=0.006$, mechanical engineering, $p<0.001$; law, $p<$ 0.001 ; social science, $p<0.001$; information science, $p<0.001$; economics, $p<0.001$; dentistry, $p=0.003$; medical science, $p<0.001$, nursing, $p=0.009$ ), which included all the STEM fields. This suggests, for example, that the low group perceived mechanical engineering as suitable for men, but the high group did not have that perception (Figure 6b). However, the low group perceived that nursing was unsuitable for men, but the high group did not have that perception (Figure 5b). Significant differences were not found in the other four fields using Fisher's test (humanities, $p=0.167$; art, $p=0.136$; music, $p=0.738$; and pharmacy, $p=0.481$ ). These results suggest that people who have lower level egalitarian attitudes for gender roles tend to have the strong stereotypical view that men are suited for STEM fields except nursing.

\section{Findings}

RQ1 was "Is there a gender bias for academic fields in Japanese public perceptions regarding suitability, employment suitability and marriage suitability?" We found that the difference in gender-gap perception of gender suitability was largest in nursing and mechanical engineering. Nursing was perceived to be the best occupation for women and mechanical engineering was perceived to be the worst. The gender-gap perception regarding marriage suitability was smaller than that for gender suitability and employment suitability.

RQ2 was "Does the perception of women's gender suitability of STEM fields differ by the level of egalitarian attitude for gender roles?" We found that the perception of women's gender suitability differed among the three groups of SESRA-S scores only for nursing, pharmacy, music, and law, which only include two STEM fields. Japanese people who scored low for their egalitarian attitude toward gender roles strongly perceived women to be better suited to these fields.

RQ3 was "Does the perception of men's suitability for STEM fields differ by the level of egalitarian attitude toward gender roles?" Significant differences were found in the 14 fields, which included all STEM fields. Japanese people who have low level of egalitarian attitude strongly perceived that STEM fields except nursing are suitable for men. 
(a) Do you think women are suited to nursing?

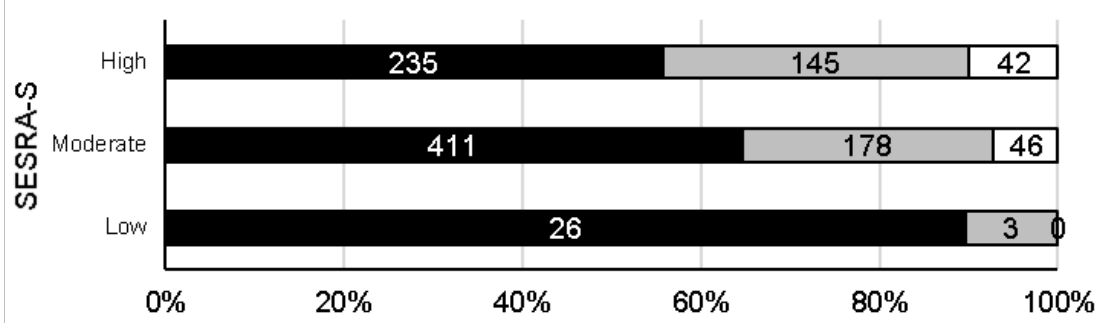

(b) Do you think men are suited to nursing?

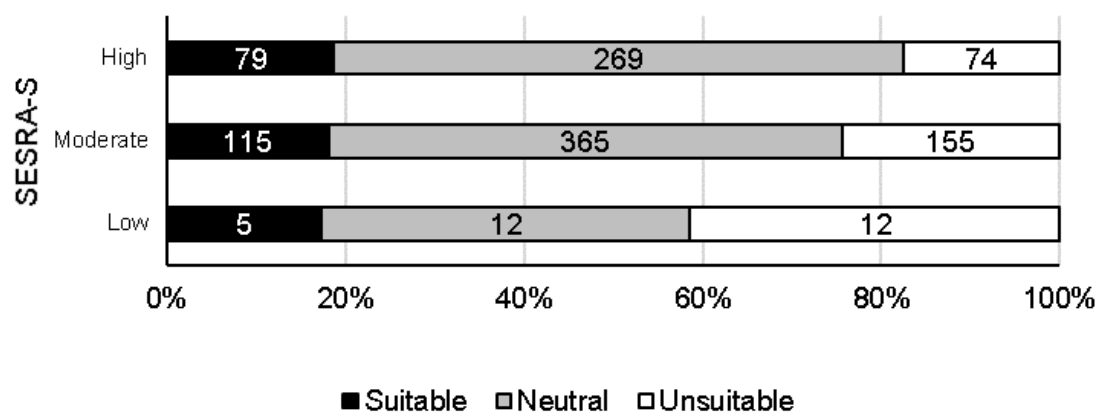

Figure 5. The relationship among the groups (low, moderate, high) and the level of agreement (suitable, neutral, unsuitable) in nursing. The low and moderate groups perceived nursing as suitable for women (a) and unsuitable for men (a). This graph shows the actual figures.

Our findings showed that perceptions for academic fields are still gender biased, although Japanese society is gradually changing. Some people still consider that STEM fields, except nursing, are suited to men, not to women. This perception has not been quantitatively measured in Japan. Proactive initiatives to change this stereotypical gender perception would be required to encourage girls to choose STEM fields.

Mechanical engineering ranked as the field to which women were least suited (Figure 2a), but moderate in terms of employment suitability (Figure 3a). A survey conducted by the Ministry of Economy, Trade and Industry (METI) showed that there will be a shortage of engineers in mechanical engineering in the next five years [Ministry of Economy, Trade and Industry, 2018]. Therefore, companies in Japan are starting to hold events to actively attract female students. The government also supports this movement. The Gender Equality Bureau Cabinet Office has organized Rikō-challenge' that encourage girls to study the STEM fields. ${ }^{6}$ This campaign has held events, including visits to STEM companies, hands-on workshops, and symposia for junior and high school students. The Japan Science and Technology Agency (JST) has also offered financial support for science meetings and hands-on workshops for Japanese junior high school students. ${ }^{7}$

\footnotetext{
${ }^{6}$ 'Rikō-challenge' (in Japanese), http:/ / www.gender.go.jp/c-challenge/.

${ }^{7}$ Joshikōseino rikeishinrosentaku puroguramu (in Japanese) [A program to support high school girls to choose science courses]', https://www.jst.go.jp/cpse/jyoshi/.
} 
(a) Do you think women are suited to mechanical engineering?

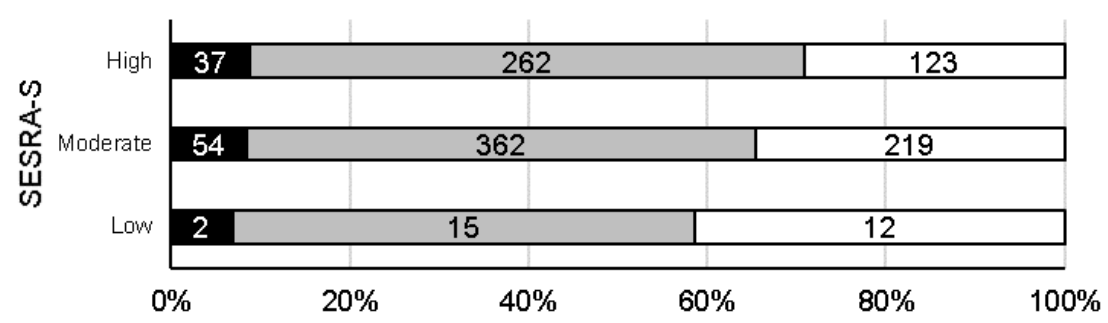

(b) Do you think men are suited to mechanical engineering?

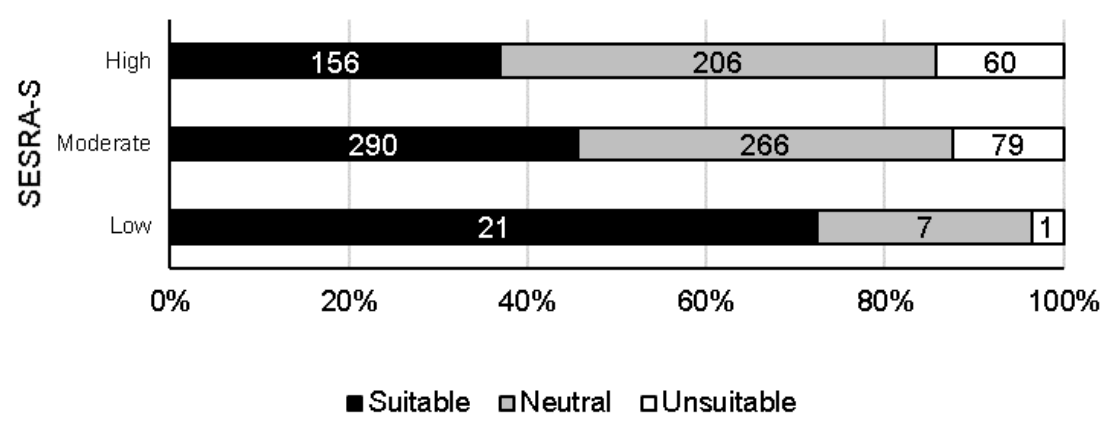

Figure 6. The relationship among the groups (low, moderate, high) and the level of agreement (suitable, neutral, unsuitable) in mechanical engineering. Low and moderate group perceived mechanical engineering as suitable for men (a), but this trend was not found in the high group (b). This graph shows the actual figures.

These campaigns should contribute to helping change the negative perceptions of engineering fields not only for students but also for the general public. However, the percentage of women in mechanical engineering has not increased significantly. Our results showed that stereotypical gender perception remains in mechanical engineering. Evidence-based initiatives to reduce the stereotypical gender perception would be required.

Regarding medical fields, general public perceptions of gender suitability and employment suitability are closely related in nursing, pharmacy, medical science, and dentistry, although some perceptions are also still gender biased, favoring nursing and pharmacy for women and medical science and dentistry for men. The proportion of female medical doctors has increased from 20 to 35 percent over the past 40 years. ${ }^{8}$ One newspaper article suggested that, due to stereotypical thinking and prejudices, some people thought that women were more likely to leave their jobs in order to raise children and that as doctors they were not as good as men. ${ }^{9}$ In addition, it was reported that there could be a public perception that medical care is a physically demanding job, ${ }^{10}$ to which men are better suited. Even

\footnotetext{
${ }^{8 ` J}$ Josei ishino nenji suii (in Japanese) [Annual trend of women doctors]', https:/ / www.mhlw.go.jp/ file/05-Shingikai-10801000-Iseikyoku-Soumuka/0000069214.pdf.

${ }^{9}$ See details in the newspaper article, "Joshigenten sabetsuto henken tōkyoidai gōkakushano 3 warini yokusei" [Reduction point for women, discrimination and prejudice, Tokyo Medical University suppressed female successful applicants to 30 percent] (August 3, 2018), Asahi Shimbun.

${ }^{10}$ Various opinions by doctors were introduced in the article. See details in "Dō omoimasuka" (in
} 
though social attitudes are changing, the masculine image of medical doctors is still deeply rooted in Japanese society. Interestingly, medical science ranked the highest for men when looking at marriage suitability, but it ranked lowest for women (Figure $4 \mathrm{a}$, Figure 4b). This might be because the work environments for medical doctors are seen as highly demanding for both men and women, and due to greater expectations of women for childcare and housework, married women may be perceived as finding it difficult to maintain a good work-life balance and they could be forced to leave the medical professions. In contrast, music ranked highest for women in the marriage suitability category (Figure 4a), and it ranked lower for men.

Music also ranked lower for employment suitability for women. These results suggest that it does not matter, for marriage suitability, whether or not women are employed. Furthermore, the fields that women can be employed in, and where they can, perhaps, earn a high salary (e.g., medical science) are actually perceived to be disadvantageous for women for marriage suitability. This may be because of the idea that wives and mothers should stay at home. Overall, these results support previous studies that have shown that levels of educational attainment for Japanese women can be used to signify their social class and culture, in that way contributing to a better marriage. In contrast, academic credentials had value for entry into professions and jobs with high income for men [Amano, 1997]. Although the social situation in Japan is changing, gender-biased attitudes regarding marriage for women are still widely held today.

We also found that egalitarian attitudes toward gender roles (SESRA-S) had a strong effect on perceptions of women's gender suitability regarding nursing. People with low SESRA-S scores had particularly strong stereotypic perceptions that nursing was good for women (Figure 5). Considering that nursing was perceived as good for women's gender suitability, being a nurse should also have been considered a good job for women. Caring fields, such as nursing, seems to be perceived as suitable for women. Although we did not directly investigate the public perception of specific jobs, nursing and medical science majors are both strongly connected to future careers, so there is likely to be a clear image in the public's mind of jobs involving hard work for both of these majors.

Additionally, most people were in the moderate group $(n=635)$. The mindset of the moderate group could be expected to be more flexible than those in the low group, or leaning toward the views of people in the low group sometimes and toward people in the high group at other times. We consider that the prevailing social atmosphere in Japan is likely to be set through the awareness of the majority (i.e., the moderate group) and that in order to change stereotypical gender-biased perceptions in society as a whole, it would therefore be better to aim to change the attitudes of people with a moderate attitude towards gender roles. For example, providing opportunities for people in the moderate category to discuss gender issues with people in the high category would be one possible solution. Just showing people in the moderate category data illustrating the current gender-biased situation in Japanese academic institutions, including this paper, could make them more aware of the problem and could possibly persuade some of them to change their attitude. Also, regarding the reason why we collected fewer responses from people in the low group, there is a possibility that the low group includes more people who do not use the Internet compared with the moderate

Japanese) [What do you think?] (August 29, 2018), Asahi Shimbun. 
and high groups, although the relationship between the level of the egalitarian attitudes and Internet use was not examined.

In this study, survey participants were limited to those who could use the Internet, as we collected their responses online. Participants who had graduated from university or graduate university were 43.28 percent $(n=470)$ of those who had received some level of higher education. This percentage was larger than the average for Japanese people overall. In a 2010 survey based on Japan's national census data, the number of people aged 20-69 and who had graduated from university or graduate university was $16,445,824$, or 23.46 percent of all Japanese people who had received an education [Statistics of Japan, 2020b]. If we had targeted all Japanese people (not just those who could use the Internet), the average level of educational attainment would have been lower than reflected in this study. Suzuki [1994] showed that as SESRA-S scores rose, so too did the level of educational attainment. Thus, the average SESRA-S score for Japanese people, as a whole, could be expected to be lower than that shown in this study, in which case the actual level of gender-biased perception could have been even higher. If this is true, our findings regarding gender-biased perceptions of nursing and mechanical engineering could have an even bigger impact on Japanese society than expected.

We consider that it will take a long time to change established public perceptions of gender suitability in Japan. However, the social situation in Japan is changing faster than ever. Recently, many Japanese have learned about other countries' situations through the Internet and social media. Some social movements (for example, the Me Too movement) are spreading among the Japanese. Some people have started to doubt established views of gender roles. Therefore, in the future our work will include longitudinal studies focusing on how public perceptions are changing.

\section{Conclusion}

In this study, we investigated the general public's perception of 18 different academic fields in Japan. We found gender-gap perceptions for gender suitability, employment suitability, and marriage suitability. In particular, nursing was perceived to be a good occupation for women, while mechanical engineering was not. These opinions were partly expressed strongly by people who had biased attitudes to gender roles. Our data showed that there are still some people with the stereotypic view that science is good for men, but not for women.

Acknowledgments This work was supported by a Japan Science and Technology Agency (JST)-RISTEX (Research Institute of Science and Technology for Society) research program (number 1005740) and the World Premier International Research Center Initiative (WPI), MEXT, Japan. 
Adachi, T. (2014). 'Occupational gender stereotypes among university students: their relationships with self-efficacy and gender role attitudes'. Japanese Association of Industrial/Organizational Psychology Journal 27 (2), pp. 87-100. URL: http://www . jaiop.jp/en/journal/429.html.

Amano, M. (1997). 'Women in higher education'. Higher Education 34 (2), pp. 215-235. https://doi.org/10.1023/A:1003051803994.

Bleeker, M. M. and Jacobs, J. E. (2004). 'Achievement in math and science: do mothers' beliefs matter 12 years later?' Journal of Educational Psychology 96 (1), pp. 97-109. https://doi.org/10.1037/0022-0663.96.1.97.

Center for Promotion of Science Education, Japan Science and Technology Agency (2010). Heisei 20 nendo kōtogakkō rikakyōin jittaichōsa hōkokusho (in Japanese). [The future of high school science education]. URL: http://www . jst .go.jp/cpse/risushien/highschool/cpse_report_009.pdf.

Cheryan, S., Ziegler, S. A., Montoya, A. K. and Jiang, L. (2017). 'Why are some STEM fields more gender balanced than others?' Psychological Bulletin 143 (1), pp. 1-35. https://doi.org/10.1037/bul0000052.

Gender Equality Bureau Cabinet Office (2018). Annual report on the state of the formation of a gender equal society 2018 (in Japanese). URL: http://www . gender. go .jp/about_danjo/whitepaper/h30/gaiyou/html/honpen/b1_s03.html.

Gonzalez, H. B. and Kuenzi, J. J. (2012). Science, Technology, Engineering and Mathematics (STEM) education: a primer. SRS report for congress R42642. U.S.A. URL: https://fas .org/sgp/crs/misc/R42642.pdf.

Ministry of Economy, Trade and Industry (2018). Rikōkeijinzai kyōkyū ni kansuru chōsa kekka wo torimatomemashita (in Japanese). [Survey results on the supply and demand situation of science and technology personnel]. URL: https://www. met i.go.jp/press/2018/04/20180420005/20180420005.html.

Ministry of Education, Culture, Sports, Science and Technology (2016). Rika ni kansuru shiryō (in Japanese). [A document about science education]. Japan. URL: http://www . mext.go.jp/b_menu/shingi/chukyo/chukyo3/060/siryo /__icsFiles/afieldfile/2016/05/12/1370460_8.pdf.

Ministry of Health, Labor and Welfare (2018). Heisei 29 nenban kōseirōdohakusyo (in Japanese). [Annual health, labour and welfare report 2017]. Japan. URL: https://www. mhlw.go.jp/wp/hakusyo/kousei/17/dl/all.pdf.

Ogawa, M., Frehill, L. M. and Huyer, S. (2012). 'Historical perspectives on women in chemistry, computer science and mathematics'. In: Blueprint for the future: framing the issues of women in science in a global context. Summary of a workshop. Washington, DC, U.S.A.: National Academies Press, pp. 73-76. URL: https://www.nap. edu/read/13306/chapter/1.

Organisation for Economic Cooperation and Development (2015). Education at a glance 2015: OECD indicators. Paris, France: OECD Publishing. https://doi.org/10.1787/eag-2015-en.

Sax, L. J., Lehman, K. J., Barthelemy, R. S. and Lim, G. (2016). ‘Women in physics: a comparison to science, technology, engineering and math education over four decades'. Physical Review Physics Education Research 12 (2), p. 020108. https://doi.org/10.1103/physrevphyseducres.12.020108.

Schiebinger, L. (1999). Has feminism change science? Boston, MA, U.S.A.: Harvard University Press.

Science Council of Japan (2016). Korekarano rikakyōikuno arikata (in Japanese). [The future of high school science education].

URL: http://www.scj.go.jp/ja/info/kohyo/pdf/kohyo-23-t224-1.pdf. 
Spencer, S. J., Logel, C. and Davies, P. G. (2016). 'Stereotype threat'. Annual Review of Psychology 67 (1), pp. 415-437.

https://doi.org/10.1146/annurev-psych-073115-103235.

Spencer, S. J., Steele, C. M. and Quinn, D. M. (1999). 'Stereotype threat and

women's math performance'. Journal of Experimental Social Psychology 35 (1), pp. 4-28. https://doi.org/10.1006/jesp.1998.1373.

Statistics of Japan (2020a). Gakkō Kihon Chōsa. [School basic survey].

URL: https://www.e-stat.go.jp/stat-search/database?page=1\&toukei=004 $00001 \&$ tstat $=000001011528$.

- (2020b). Kokuzei chōsa. [Census]. URL: https://www.e-stat.go.jp/stat-search $/$ files?page $=1 \& l$ ayout $=$ datalist\&touke $i=00200521 \&$ tstat $=000001039448 \& \mathrm{cyc}$ le $=0 \& t c l a s s 1=000001047544 \&$ tclass $2=000001050184$.

Suzuki, A. (1991). 'Egalitarian sex role attitudes: reliability and validity of SESRA (english form) and comparison of American and Japanese women'. Research in Social Psychology 6 (2), pp. 80-87. https://doi.org/10.14966/jssp.KJ00003725131.

Suzuki, A. (1994). 'Construction of a short-form of the scale of egalitarian sex role attitudes (SESRA-S)'. The Japanese journal of psychology 65 (1), pp. 34-41. https://doi.org/10.4992/jjpsy.65.34.

Ueno, C. (2018). Onna girai: Nippon no Misojin̄̄ (in Japanese). [Women hating]. Tokyo, Japan: Asahi Shimbun Publications Inc.

Ui, M. (2001). 'Jenda Seiyakuwari (in Japanese)'. [Gender and gender roles]. In: Shinri Sokutei Syakudoshu II. [Psychometric Scale Collection II]. Ed. by H. Hori and M. Yamamoto. Tokyo, Japan: SAIENSU-SHA Co. Ltd.

Uji, M., Shono, M., Shikai, N., Hiramura, H. and Kitamura, T. (2006). 'Egalitarian sex role attitudes among Japanese human service professionals: confirmatory factor analytic study'. Psychiatry and Clinical Neurosciences 60 (3), pp. 296-302. https://doi.org/10.1111/j.1440-1819.2006.01505.x.

World Economic Forum (2018). The global gender gap report 2018. URL: https: //www .weforum.org/events/world-economic-forum-annual-meeting.

Authors

Yuko Ikkatai is a project researcher at the Kavli Institute for the Physics and Mathematics of the Universe, the University of Tokyo. Her research interests are science communication, citizen science and animal psychology.

E-mail: y.ikkatai@gmail.com.

Azusa Minamizaki is a researcher at Kobayashi-Maskawa Institute for the Origin of Particles and the Universe, Nagoya University. Her research interests are science communication in physics, astronomy and big science.

E-mail: minamizaki@kmi.nagoya-u.ac.jp.

Kei Kano, $\mathrm{PhD}$, is an associate professor at the Science Communication Laboratory, Graduate School of Education, Shiga University, Japan. He has worked widely in science communication or public engagement for grade school students, adults, and early-career scientists. Dr. Kano is interested in inclusiveness of science communication or public engagement activities. E-mail: kkano@edu.shiga-u.ac.jp.

Atsushi Inoue is a researcher at Nippon Institute for Research Advancement. His research interests are economics of education, education policy.

E-mail: ainoue@nira.or.jp. 
Euan McKay is project assistant professor at the Division for Strategic Public Relations, the University of Tokyo. His research interests are communication, diversity and history. E-mail: euan.mckay@mail.u-tokyo.ac.jp.

Hiromi M. Yokoyama is professor at the Kavli Institute for the Physics and Mathematics of the Universe, the University of Tokyo. Her research interests are science communication and public policy. E-mail: hiromi.yokoyama@ipmu.jp.

How to cite

Ikkatai, Y., Minamizaki, A., Kano, K., Inoue, A., McKay, E. and Yokoyama, H. M. (2020). 'Gender-biased public perception of STEM fields, focusing on the influence of egalitarian attitudes toward gender roles'. JCOM 19 (01), A08.

https://doi.org/10.22323/2.19010208. 